\title{
Experimental Organism Benign Neuroendocrine Cell Tumor
}

National Cancer Institute

\section{Source}

National Cancer Institute. Experimental Organism Benign Neuroendocrine Cell Tumor.

NCI Thesaurus. Code C126086.

A benign neoplasm arising from neuroendocrine cells. 